\title{
Recent methodological advances in male hormonal contraception
}

\author{
Peter Y. Liu ${ }^{1,2}$, Ronald S. Swerdloff ${ }^{1}$, and Christina Wang ${ }^{1,}{ }^{*}$ \\ ${ }^{1}$ Division of Endocrinology, Department of Medicine, Harbor-UCLA Medical Center and Los \\ Angeles Biomedical Research Institute (LA BioMed) at Harbor-UCLA Medical Center, Torrance, CA \\ 90509 \\ ${ }^{2}$ Endocrine and Metabolic Group, Woolcock Institute of Medical Research University of Sydney and \\ Concord Hospital
}

\begin{abstract}
Landmark WHO-sponsored trials showed decades ago that male hormonal contraception (MHC) is an effective male-directed contraceptive approach. Considerable progress has been made particularly in the last 5 years, establishing for the first time the reversibility of MHC and its short-term safety. Methodological advances in recent years include: the pooling of information and individual-level integrated analysis; the first-time use of centralized semen analysis and fluorescence to detect low sperm concentrations; the establishment of sperm quality reference ranges in fertile men; the measurement of blood steroid concentrations by gas or chromatography/mass spectrometry; and the inclusion of placebo groups to delineate clearly possible adverse effects of androgens and progestins in men. We report integrated analyses of factors that are important in predicting suppression and recovery of spermatogenesis after MHC clinical trials for the past 15 years. These are the best data available and will provide guidance and reassurance for the larger scale Phase III specific regimen efficacy studies that will be required to bring MHC to the population (market).
\end{abstract}

\section{Keywords}

Contraception; male; recovery; suppression; semen; androgen; progestin

\section{Introduction}

Hoping to find a partner and start a family are near universal human desires. Fulfilling these expectations requires planning to space and limit pregnancies according to each couple's social, personal and financial constraints. Broadening contraceptive choice to allow men and women to both share family planning responsibilities would facilitate these important individual and societal needs. However, few candidate male-directed approaches have been extensively studied, and none have undergone pivotal clinical investigations sufficient for drug or device registration purposes. Here, we review the most comprehensively researched experimental male-directed method, namely, male hormonal contraception (MHC). This hormonally-based approach combines androgen-progestin treatment regimens and exploits negative sex hormone feedback suppression of pituitary gonadotropin secretion to reduce sperm output and thereby

\footnotetext{
*Corresponding author: Christina Wang, MD, General Clinical Research Center, Division of Endocrinology, Department of Medicine, Harbor-UCLA Medical Center and Los Angeles Biomedical Research Institute (LA BioMed) at Harbor-UCLA Medical Center, Torrance, CA 90509, Telephone: (310) 222-2503, FAX: (310) 533-6972, wang @labiomed.org.

Publisher's Disclaimer: This is a PDF file of an unedited manuscript that has been accepted for publication. As a service to our customers we are providing this early version of the manuscript. The manuscript will undergo copyediting, typesetting, and review of the resulting proof before it is published in its final citable form. Please note that during the production process errors may be discovered which could affect the content, and all legal disclaimers that apply to the journal pertain.
} 
regulate male fertility [1-4]. The mechanism of action is analogous to inhibition of ovulation by combined estrogen-progestin contraceptives, of which multiple hormonal combinations, doses and delivery systems are available. In contrast, not even a single MHC regimen is marketed anywhere in the world.

Features of an ideal male-directed contraceptive method are outlined in Table 1. In this respect, the two currently available male-directed methods are not widely acceptable because vasectomy requires a simple surgical procedure but is not easily reversible whereas condoms have limited user efficacy and acceptability. Although still investigational, recently completed crucial studies have markedly progressed our understanding of the contraceptive effectiveness, reversibility and short-term safety of MHC and confirm that this method may satisfy many of the requirements for an ideal male-directed method [5-8].

\section{MHC methods are effective}

Landmark decades old World Health Organization (WHO)-sponsored proof of concept studies have clearly shown that testosterone therapy profoundly suppresses spermatogenesis and prevents pregnancies $[9,10]$. These observations have since been replicated with a longeracting testosterone preparation $[8,11]$, and also using an androgen-progestin combination [12] suggesting the generalizability of this approach. The contraceptive efficacy of these preparations and regimens are summarized in Table 2. Contraceptive efficacy rates of $98.8 \%$ for MHC are reported and compare favorably with first year use of the oral contraceptive pill by women [13]. Nevertheless, available MHC efficacy data is limited by relatively low overall exposure, especially for androgen-progestin combinations (Table 2). However, before MHC can be available to the population, larger scale efficacy/safety studies sufficient for drug regulatory agency approval have to be conducted [8].

The relationships among semen quality (particularly sperm concentration), fertility and contraceptive efficacy collectively suggest that reliable contraception can be expected if sperm concentration is suppressed to very low levels, i.e., below $1 \times 10^{6} \mathrm{sperm} / \mathrm{ml}[4,10,13,14]$. Indeed, the clinical assessment of male fertility has for decades relied upon semen analysis and reference values collected from fertile men in different parts of the world are now available [14]. Investigating male-directed contraceptive methods through this recognized and valid surrogate measure of male fecundity is therefore illuminating. Using semen quality as the outcome, information from over 3000 person-years of hormonal exposure has already been collected [5-8]. However, androgen-progestin combinations have been administered to less than one-fifth of men in these studies and hence an important gap in knowledge remains. Expert opinion considers a sperm concentration of no more than $1 \times 10^{6} \mathrm{sperm} / \mathrm{mL}$ as suitable for reliable contraception $[15,16]$. Nevertheless, even at such low sperm concentrations, contraceptive failures may still occur [8]. Recent data now show a failure rate of 1.1 (95\% confidence interval 0.4 - 3.7) per 100 person-years with a sperm concentration of no more than $1 \times 10^{6} \mathrm{sperm} / \mathrm{mL}$ calculated by life-table analysis over 24 months, although paternity and actual sperm concentration at the time of conception can only be assumed [8].

\section{The universal suppressibility of spermatogenesis and applicability of MHC: unrealistic expectations?}

Modern androgen and androgen-progestin combinations report suppressibility in 80-95\%, of men in clinical trials lasting up to 24 months $[7,11,12]$. Whether MHC methods can be universally applied to all men is not known, and cannot be determined until lead candidate regimens have been fully optimized and tested in large-scale clinical trials equivalent to the requirement of a new female contraceptive method. 
Optimization includes the co-administration of progestin with an androgen for contraceptive purposes since this markedly enhances both the rate and extent of spermatogenic suppression by up to two fold [6]. Hence, the paucity of androgen-progestin hormonal exposure information with contraceptive efficacy as a primary endpoint is an important limitation for the field (see Section 2). Whether a specific progestin is superior to another progestin is also unknown, but likely to be the case because progestins differ in anti-ovulatory potency, ability to support pregnancy, and binding and specific activation of progesterone relative to other steroid receptors [17]. Available analyses in humans have been underpowered to determine whether certain progestins more effectively suppress sperm output than others [6].

Optimization may also involve varying the dose or delivery system of testosterone administered during treatment. Increasing testosterone dose could theoretically increase intratesticular testosterone if the maximal limit to testosterone-dependent feedback inhibition of gonadotropin secretion has already been reached. Whether such minor increases in intratesticular testosterone are sufficient to promote spermatogenesis is not directly known in humans, but is relevant in rodents and other primates [18-20]. Furthermore, some reports are available relating higher dose testosterone with incomplete suppression of sperm output during MHC [6,21,22] and postulated that high dose testosterone therapy to ensure rapid suppression of sperm output should then be followed by dose reduction for maintenance of severe oligozoospermia. Whether this postulated dose optimization regimen can actually decrease the rate of sperm rebound observed in large studies $[7,8,10]$ requires further investigation.

Nevertheless, it seems unlikely that universal suppression of sperm output in all men is a realistic expectation meaning that MHC may not be suitable for a small sub-group (minority) of men. Adequate sperm suppression would then also need to be verified in everyone, although the inconvenience (not required for female methods) may be minimal with the advent of expedient FDA-approved sensitive home semen testing kits (e.g., SpermCheck Vasectomy® Contravac, Inc, Charlottesville VA). Lessons from the development of female-directed hormonal methods show that universal applicability is both unrealistic and unnecessary. Female hormonal methods cannot be used by some women due to past breast cancer, thromboembolism, migraine headaches or older age and hence are not universally applicable. Breakthrough ovulation due to method failure or non-compliance also occurs and no single method is used by all women. In this context, it may be more important to provide a range of different options because no single method can be expected to be ideal for every couple.

Predicting which men would or would not be suitable for MHC is a further challenge. Younger age, lower initial blood testosterone or semen sperm concentrations predict faster suppression of sperm output [6], but the statistical effect sizes effect sizes are small and hence these factors are unlikely to be clinically useful. The overall effect of ethnicity is also confusing since Caucasian men suppressed sperm output faster initially, but ultimately to a less complete extent than Asian men [6,23]. Reliably predicting which men will fail to adequately suppress sperm output is unlikely to be possible with conventional clinical or laboratory data. Whether pharmacogenetic approaches will prove to be decisive requires further investigation.

\section{MHC methods are reversible}

Full recovery of spermatogenesis to levels consistent with normal male fertility is a realistic expectation for all men after cessation of MHC regimens [5]. Non-recovery of sperm output has only been reported in two men in whom intercurrent sterilizing processes such as myotonic dystrophy [12] and epididymitis [8] intervened. A median time of 4 to 5 months is required for sperm concentrations to return to $20 \times 10^{6} \mathrm{sperm} / \mathrm{mL}$, and by 12 months over $90 \%$ of men have recovered sperm output to thresholds compatible with normal male fertility [5]. A variety of co-variables influence the rates but not extent of recovery, although statistical effect sizes 
are relatively minor (Table 3). Nevertheless, these data provide the strongest assurance of highly predictable recovery to normal semen quality following MHC. Although reassuring, important caveats include the lack of therapies that exceeded 18 months duration and the limited number of men of African or Hispanic origin. Longer treatment studies in more diverse populations of men are required.

\section{The short-term side effects of MHC methods are now well-defined}

Large uncontrolled studies have reported many short-term adverse effects (Table 4) [7-9]. A recent study [7], which included a placebo group for the first time, showed that adverse events were self-reported by $93 \%$ of men on active treatment, but also by $81 \%$ of men on placebo therapy! Although the inclusion of placebo controls was unprecedented in the field, such placebo controls are not ethically justifiable in contraceptive efficacy studies as unwanted pregnancies would occur. For this reason, semen analysis remains indispensable during MHC development.

The frequency of complaints was doubled in men receiving active treatment (20\% versus $8 \%$, on average) consistent with increased hormone exposure (increased acne, weight gain, night sweats and more frequent changes in libido or mood) compared with those receiving placebo [7] (Table 4). Although adverse events were generally mild, the increases were statistically significant. HDL cholesterol also fell by about $10 \%$ (consistent with many MHC studies), but proportionally with total cholesterol and neither change was statistically significant. The clinical relevance of these minor lipid changes is uncertain given emerging understanding of reverse cholesterol transport [24]. More or other adverse events could occur with longer exposure of young men to MHC. However, long-term adverse cardiovascular or prostate effects will still require Phase IV studies to fully define since prolonged exposure of young men to androgens and progestins cannot be fully assessed until a MHC method is available. Potential cardiovascular effects may actually be beneficial $[25,26]$, but further work is needed. Potential adverse effects on prostate gland growth may be circumvented with the development of selective androgen receptor modulators (SARMs) that could theoretically suppress gonadotropin secretion more profoundly (possibly by exhibiting specific progestogenic properties and minimal 5- $\alpha$ reducibility), but possess reduced androgenic side effects. Proof of concept includes the development of 7- $\alpha$ methyl-19-nor-testosterone (MENT) by the Population Council as a modified androgen that has less prostate-stimulating activity [2729].

\section{MHC is acceptable to couples}

Multiple studies from many populations worldwide consistently show that MHC is acceptable to couples [30-36]. MHC acceptability is reviewed elsewhere in this issue.

\section{Onset of action of MHC is delayed by 2 to 3 months}

As outlined (see section 3.), potentially 80-95\% of all men will suppress sperm output to concentrations compatible with reliable contraception within 2 to 3 months [7,11,12] and this compares favorably with the disappearance of sperm after vasectomy [37]. Although delayed onset of action is a nuisance, such a delay could be acceptable to many men if the alternative is vasectomy. Indeed, given that the spermatogenic cycle is about 70 days, rapid onset male contraception may not be possible for particular methods that target processes which occur early during spermatogenesis. Further optimization could include innovations such as coadministration of other agents which directly and rapidly reduce sperm output. Such compounds could be administered initially to allow rapid onset of action, but then progressively be withdrawn to allow maintenance of oligozoospermia by hormonal methods alone. Such an approach might be advantageous for cost or safety reasons. Although gonadotropin-releasing 
hormone $(\mathrm{GnRH})$ antagonists have been applied in this context, these act indirectly through suppression of gonadotropins and hence may not be effective in preventing putative gonadotropin-independent spermatogenesis which may arise from intrinsic testicular androgen action or production. Agents that directly suppress steroidogenesis in addition to suppressors of gonadotropins have not been studied in MHC clinical trials.

\section{Other methodological advances}

As highlighted in this review, considerable progress has been made in documenting the effectiveness, reversibility and short-term safety of MHC, particularly in the last 5 years. Methodological advances during this time include the pooling of information and individuallevel integrated analysis [5,6], the first-time use of centralized semen analysis and fluorescence to detect low sperm concentrations [7], the establishment of sperm quality reference ranges in fertile men [14], the accurate and precise measurement of blood steroid concentrations by gas or liquid chromatography/tandem mass-spectrometry [7] and the use of placebo to define the adverse effects ascribed to the hormonal therapy. More work needs to be done to extend these findings to more diverse populations and with candidate androgen-progestin combinations since progestin co-administration is now shown to be essential for timely and reliable suppression of spermatogenesis. Further optimization of methods, compounds and strategies is required.

\section{Conclusions}

We conclude that androgen-progestin contraceptive regimens: (i) can be widely applied to many men of differing age and other baseline characteristics, although direct verification in African and Hispanic cohorts would be desirable [5,6]; (ii) are superior to androgens administered alone and time of onset of contraceptive action compares favorably with vasectomy [6,37]; and, (iii) allow spermatogenesis to fully recover to levels consistent with normal male fertility in all men following cessation of androgen with and without progestin treatments [5]. Further studies developing, optimizing and conducting trials of a candidate androgen-progestin combination are needed.

\section{Acknowledgments}

This review was supported by the Australian National Health and Medical Research Council through Career Development Award \#511929, the Endocrinology, Metabolism and Nutrition Training Grant T32 DK007571, MO1 RR00425 to the General Clinical Research Center at Harbor-UCLA Medical Center, and research funds from Los Angeles Biomedical Research Institute.

\section{References}

1. Page ST, Amory JK, Bremner WJ. Advances in male contraception. Endocr Rev 2008;29:465-93. [PubMed: 18436704]

2. Liu, PY.; Veldhuis, JD. The hypothalamo-pituitary unit, testis and male accessory organs. In: Strauss, JF.; Barbieri, RL., editors. Yen and Jaffe's Reproductive Endocrinology: Physiology, Pathophysiology and Clinical Management. 6. Philadelphia: W. B. Saunders; 2009. p. 283-98.

3. Anderson RA, Baird DT. Male contraception. Endocr Rev 2002;23:735-62. [PubMed: 12466187]

4. Nieschlag E. Male hormonal contraception: love's labour's lost? J Clin Endocrinol Metab 2009;94:1890-2. [PubMed: 19494165]

5. Liu PY, Swerdloff RS, Christenson PD, Handelsman DJ, Wang C. Hormonal Male Contraception Summit Group. Rate, extent and modifiers of spermatogenic recovery after hormonal male contraception: An integrated analysis. Lancet 2006;367:1412-20. [PubMed: 16650651] 
6. Liu PY, Swerdloff RS, Anawalt BD, et al. Determinants of the rate and extent of spermatogenic suppression during hormonal male contraception: An integrated analysis. J Clin Endocrinol Metab 2008;93:1774-83. [PubMed: 18303073]

7. Mommers E, Kersemaekers WM, Elliesen J, et al. Male hormonal contraception: a double-blind placebo-controlled study. J Clin Endocrinol Metab 2008;93:2572-80. [PubMed: 18413423]

8. Gu Y, Liang X, Wu W, et al. Multicenter contraceptive efficacy trial of injectable testosterone undecanoate in Chinese men. J Clin Endocrinol Metab 2009;94:1910-5. [PubMed: 19293262]

9. WHO Task Force on Methods for the Regulation of Male Fertility. Contraceptive efficacy of testosterone-induced azoospermia in normal men. Lancet 1990;336:955-9. [PubMed: 1977002]

10. WHO Task Force on Methods for the Regulation of Male Fertility. Contraceptive efficacy of testosterone-induced azoospermia and oligozoospermia in normal men. Fertil Steril 1996;65:821-9. [PubMed: 8654646]

11. Gu YQ, Wang XH, Xu D, et al. A multicenter contraceptive efficacy study of injectable testosterone undecanoate in healthy Chinese men. J Clin Endocrinol Metab 2003;88:562-8. [PubMed: 12574181]

12. Turner L, Conway AJ, Jimenez M, et al. Contraceptive efficacy of a depot progestin and androgen combination in men. J Clin Endocrinol Metab 2003;88:4659-67. [PubMed: 14557437]

13. Waites GM. Development of methods of male contraception: impact of the World Health Organization Task Force. Fertil Steril 2003;80:1-15. [PubMed: 12849793]

14. Cooper, TG.; Noonan, E.; von Eckardstein, S., et al. World Health Organization reference values for human semen characteristics. Hum Reprod Update. 2009. available at: http://humupd.oxfordjournals.org/cgi/content/abstract/dmp048v2

15. Anonymous. Tenth summit meeting consensus: recommendations for regulatory approval for hormonal male contraception. Int J Androl 2007;30:63-4.

16. Anonymous. Sixth Summit Meeting Consensus: Recommendations for Regulatory Approval for Hormonal Male Contraception. Int J Androl 2002;25:375.

17. Sitruk-Ware R. New progestagens for contraceptive use. Hum Reprod Update 2006;12:169-78. [PubMed: 16291771]

18. Weinbauer GF, Gockeler E, Nieschlag E. Testosterone prevents complete suppression of spermatogenesis in the gonadotropin-releasing hormone antagonist-treated nonhuman primate (Macaca fascicularis). J Clin Endocrinol Metab 1988;67:284-90. [PubMed: 3292557]

19. Weinbauer GF, Khurshid S, Findscheidt U, Nieschlag E. Sustained inhibition of sperm production and inhibin secretion by a gonadotrophin-releasing hormone antagonist and delayed testosterone substitution in non-human primates (Macaca fascicularis). Acta Endocr 1989;123:303-10.

20. Handelsman DJ, Spaliviero JA, Simpson JM, Allan CM, Singh J. Spermatogenesis without gonadotropins: maintenance has a lower testosterone threshold than initiation. Endocrinology 1999;140:3938-46. [PubMed: 10465262]

21. Meriggiola MC, Costantino A, Bremner WJ, Morselli-Labate AM. Higher testosterone dose impairs sperm suppression induced by a combined androgen-progestin regimen. J Androl 2002;23:684-90. [PubMed: 12185103]

22. Michel E, Bents H, Akhtar FB, et al. Failure of high-dose sustained release luteinizing hormone releasing hormone agonist (buserelin) plus oral testosterone to suppress male fertility. Clin Endocrinol (Oxf) 1985;23:663-75. [PubMed: 3938352]

23. Handelsman DJ, Farley TM, Peregoudov A, Waites GM. Factors in nonuniform induction of azoospermia by testosterone enanthate in normal men. World Health Organization Task Force on Methods for the Regulation of Male Fertility. Fertil Steril 1995;63:125-33. [PubMed: 7805901]

24. Shabsigh R, Katz M, Yan G, Makhsida N. Cardiovascular issues in hypogonadism and testosterone therapy. Am J Cardiol 2005;96:67M-72M. [PubMed: 15979436]

25. Liu PY, Death AK, Handelsman DJ. Androgens and cardiovascular disease. Endocr Rev 2003;24:313-40. [PubMed: 12788802]

26. Wu FC, von Eckardstein A. Androgens and coronary artery disease. Endocr Rev 2003;24:183-217. [PubMed: 12700179]

27. Sundaram, K.; Kumar, N.; Bardin, CW. 7a-methyl-19-nortestosterone (MENT): an ideal androgen for replacement therapy. In: Bhasin, S.; Gabelnick, HL.; Spieler, JM.; Swerdloff, RS.; Wang, C.; 
Kelly, C., editors. Pharmacology, Biology, and Clinical Applications of Androgens. New York: Wiley-Liss; 1996. p. 493-7.

28. Anderson RA, Martin CW, Kung AW, et al. 7-alpha-19-nortestosterone maintains sexual behavior and mood in hypogonadal men. J Clin Endocrinol Metab 1999;84:3556-62. [PubMed: 10522995]

29. Von Eckardstein S, Noe G, Brache V, et al. A clinical trial of 7alpha-methyl-19-nortestosterone implants for possible use as a long-acting contraceptive for men. J Clin Endocrinol Metab 2003;88:5232-9. [PubMed: 14602755]

30. Amory JK, Page ST, Anawalt BD, Matsumoto AM, Bremner WJ. Acceptability of a combination testosterone gel and depot medroxyprogesterone acetate male contraceptive regimen. Contraception 2007;75:218-23. [PubMed: 17303493]

31. Meriggiola MC, Cerpolini S, Bremner WJ, et al. Acceptability of an injectable male contraceptive regimen of norethisterone enanthate and testosterone undecanoate for men. Hum Reprod 2006;21:2033-40. [PubMed: 16731547]

32. Heinemann K, Saad F, Wiesemes M, White S, Heinemann L. Attitudes toward male fertility control: results of a multinational survey on four continents. Hum Reprod 2005;20:549-56. [PubMed: 15608042]

33. Weston GC, Schlipalius ML, Bhuinneain MN, Vollenhoven BJ. Will Australian men use male hormonal contraception? A survey of a postpartum population. Med J Aust 2002;176:208-10. [PubMed: 11999235]

34. Glasier AF, Anakwe R, Everington D, et al. Would women trust their partners to use a male pill? Hum Reprod 2000;15:646-9. [PubMed: 10686212]

35. McLachlan RI, McDonald J, Rushford D, Robertson DM, Garrett C, Baker HW. Efficacy and acceptability of testosterone implants, alone or in combination with a 5alpha-reductase inhibitor, for male hormonal contraception. Contraception 2000;62:73-8. [PubMed: 11102590]

36. Martin CW, Anderson RA, Cheng L, et al. Potential impact of hormonal male contraception: crosscultural implications for development of novel preparations. Hum Reprod 2000;15:637-45. [PubMed: 10686211]

37. Marwood RP, Beral V. Disappearance of spermatozoa from the ejaculate after vasectomy. Br J Med 1979;1:87. 
Table 1

Features of an ideal male-directed (hormonal) contraceptive

- $\quad$ High efficacy

○ Universally effective (i.e., can be used by all men)

$\circ$ Equivalent to female-directed methods

- Reversible

- Safe

○ Short-term side effects

$\circ$ Long-term health risks

- Acceptable to couples

$\circ$ Convenient

○ Economical

- Rapid onset of action and recovery

- Affordable and available 
Table 3

Predictors of faster recovery of sperm output after cessation of MHC

- Older age

- Asian race

- $\quad$ Shorter treatment duration

- Higher baseline sperm concentrations

- Faster initial suppression of sperm output

- Lower baseline serum luteinizing hormone (LH) concentrations

- Shorter acting testosterone preparations 


\section{Table 4}

Short-term adverse effects of MHC

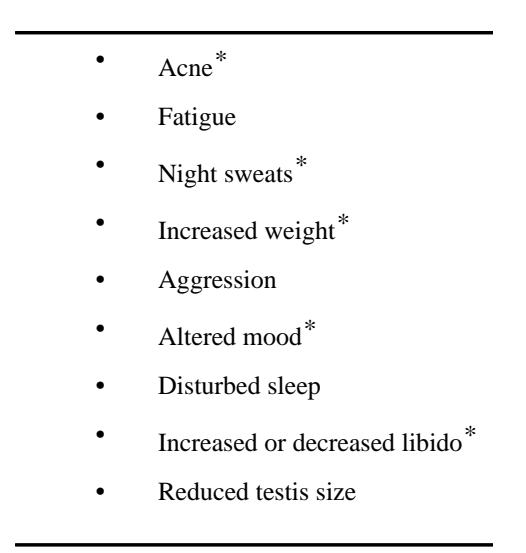

* Adverse effects verified in a placebo-controlled trial [7]. 